\title{
Development of Modern Technology in Electronic Engineering
}

\author{
Fang Liu \\ College of Physics and Electronic Information, Baicheng Normal University, \\ Baicheng,137000,China \\ email: bcsfxywlx@163.com
}

Keywords: Electronic Engineering, modern technology, application scope, development survey

\begin{abstract}
The rapid development of science and technology provides reliable protection for the expansion of electronic engineering applications, and gradually improves the production efficiency of related industries. With the influence of this situation, in order to meet the people's demand for electronic engineering, we need to expand the scope of these technologies' application, to promote the construction of electronic engineering, and to pay attention to the rational use of different professional technologies. Combined with the actual development of the current electronic engineering in our country, we know that the application of modern technology related is still facing great challenges. There is a certain gap between the western developed countries and us. We need to take necessary measures to promote the constant development of the technology. Based on this, we will expound the relevant contents of the modern electronic engineering technology development systematically, so as we can provide effective reference information for related research work, and enhance the overall level of electronic engineering construction in our country.
\end{abstract}

\section{Introduction}

In order to expand the scope of electronic engineering services and promote the rapid development of the economy, we need to notice that electronic engineering modern technology can meet the actual production demand from all walks of life to society, and drive the constant development of the technology. So that the modern technology of electronic engineering in China can meet the actual needs of all sectors of society, and enhance the applicability of various technologies. To achieve such development goals, we should have a certain degree of understanding of development trend in modern electronic engineering technology and electronic engineering; formulate effective measures to expand the application scope of modern technology; gradually narrow the gap between the developed countries and the western developed countries. At the same time, we need to improve the modernization of electronic engineering industry standards, to promote the use of these technologies to achieve the desired results.

\section{The Relevant Contents of Modern Electrical Engineering Technology}

With the advent of the information era, it has put forward higher requirements on the reliability of the technical performance of electronic engineering modernization. The technical performance should combine with the specific requirements of actual production activities. We should focus on a variety of flexible use in electronic engineering technology, and promote the rapid development of related industries [1]. At present, electronic engineering technology applications are gradually expanding. Various technologies face a great challenge in long-term. So we need to strengthen the relevant personnel to study in-depth of the modern electronic engineering technology. We should maximize effectiveness of these technologies; improve the comprehensive market competitiveness of the electronics industry.

As an independent discipline, electronic engineering has achieved necessary processing of electronic information through effective using of information technology and computer network [2]. These developments boost the efficiency of electronic information resources integration indirectly and optimize the working performance of various kinds of electronic equipment.

Under the current situation, it's obvious that all kinds of business of electronic engineering 
technology modernization are fusing. The speed of the related industry chain differentiation is also accelerating. These promote the coordinated development of the industries and provide a reliable guarantee for the emerging industries to enhance the level of business. Therefore, with the relevant requirements of the knowledge economy, we need to push up the overall development level of the modern technology of electronic engineering and formulate various policies to support the modernization of electronic engineering technology development, so to make sure the wide future of these technologies [3].

\section{The Trend Analysis of Electronic Engineering Development}

In the long process of development, electronic engineering has made a series of theoretical results. The theoretical system of electronic engineering is gradually perfect; the related product development cycle is obviously shortened, so it has a positive impact on the stable development of economy and society [4]. Combining with actual requirements of the current application status of electronic engineering and related production activities, we know that the analysis focusing on the development trend of electronic engineering is necessary. Not only it conducive to the promotion of the overall development level of related products, but also optimizes the economic structure of our country indirectly and realizes the efficient use of the electronic information resources.

The future development of electronic engineering embodied in these aspects: (1) It can promote the related industry chain business differentiation, and accelerate the fusion speed [5]; (2) Electronic engineering technology modernization will play a greater role in the economic and social development; (3) In a certain period of time, electronic engineering will gradually promote the rapid development of related industries and provide more quality service for the society. A good chain development model will be formed within a certain period of time.

\section{Important Measures to Promote the Development of Electronic Engineering Modernization}

Create External Environment to Meet the Development Needs of Electronic Engineering Modernization. A variety of policy, intensify policy support. In order to promote the steady development of modern technology and create a good external environment, countries need to develop more policies to increase support for electronic engineering modernization technology research projects [6]. To speed up the development of modern technology, countries provide the necessary driving force to promote the technology meeting the requirements of the times, and gradually expand the scale of the electronic industry. To achieve development goals, we need to do these things: the state should formulate various policies according with these industries strategic and invest in related industries; electronics industry with large development potential and capital turnover difficult should broaden its financing channels for it can speed up to create favorable conditions; in the field of computer range, the state should set the necessary incentive mechanism in the process of developing various policies; improve the mechanism of electronic industry market; establish Electronic Engineering Professional Committee; ensure the healthy development of the electronic industry; create a good external environment for the development of modern electronic engineering technology.

Attach importance to scientific and technological support. In order to promote the development of modern electronic engineering technology and expand the application range of electronic technology, countries need to pay attention to science and technology support. Countries need to guide the actual development situation of electronic engineering market; improve the overall market competitiveness of modern electronic engineering enterprises. Countries need to focus on science and technology support, provide a good external environment for the goal of modernization in the development of electronic engineering technology. Therefore, countries need to formulate relevant policies in the process of actual demand, they should be fully considered in the technology industry. The state should conduct professional guidance on the relevant indicators of electronic engineering modernization technology, give it more support, and realize the steady development of electronic engineering modernization technology. 
Focus on legislative protection of intellectual property rights. In order to promote the development of modern electronic engineering technology, enterprises should strengthen the awareness of independent innovation; study on the key technology of the enterprise increase; establish integrated circuit industry system with reliable performance and enhance the overall level of competition in electronic engineering technology. In order to achieve such development goals, the relevant departments need to pay attention to the protection of legislation intellectual property rights; strengthen the formulation and implementation of intellectual property law; provide a reliable guarantee for the stable development of the modern technology. At the same time, the country should strengthen comprehensive evaluation; strengthen law enforcement; strengthen protection of the actual effect, to prompted the r\&d staff can keep enough enthusiasm in the working process. Therefore, in order to broaden the some technical services, technicians need to strengthen the awareness of legislation protection and improve the specific protection mechanism to meet the actual development requirements of the electronic engineering industry.

Safeguard Measures to Enlarge the Range of Modern Electrical Engineering Technology Application. Intensify the training of professional talents. As an important factor affecting the modern technology of electronics and engineering application to expand the scope of the strategy, whether it is reasonable professional talents formulating and talent strategy meet the actual demand of modern electronic engineering technology development [7]. It will make a great impact on the future of electronic engineering technology modernization development goals. Therefore, to enhance the training of talents in Electronic Engineering with the development of electronic engineering enterprises, we need to practice and pay attention to the cultivation of talents of innovation in the process of modernization. Electronic engineering technology development needs to be an important orientation of talent training which focuses on the transformation of the traditional human resource management; increase the integration of resources, optimize the electronic engineering professional and technical personnel structure. The talent cultivation goal can be achieved smoothly in a certain period of time with more vitality for modern electronic engineering technology development force. At the same time, in the process of talents in electronic engineering professional training, these personnel need to master learning ability, flexible use of knowledge ability, electronic engineering market information sensitivity, research ability and other aspects. These can achieve effective and comprehensive quality of professional talents in electronic engineering support.

Talent training combined with electrical engineering enterprise needs. In the process of training the electronic engineering technology professional talents, we should fully consider the actual demand of enterprise for all kinds of technical personnel. We can work out practical and effective training measures to ensure the quality of personnel training. At the same time, as electronic engineering enterprise should give the college graduates, sea turtles, social workers and other people corresponding development platform combined with their different education levels; arise different personnel working potential; give full play to their professional advantages. So we can achieve the rapid development of modern electrical engineering technology.

Pay attention to the effective construction of enterprise economic growth point. In the combination process of electrical engineering products and research and development project, we should analyze the actual development of the electronic engineering technology in current state. In electronic engineering enterprise, economic growth point is a benchmark. We make synthetically evaluation in application prospect of various electronic engineering technologies. Improving the relevant service system, enriching variety of electronic equipment, optimizing the equipment performance, all these can make modern electrical engineering technology development achieve the actual development of enterprise economic benefit increased. Therefore, we need to pay attention to effective construction of enterprise economic growth point in electronic engineering. So we can provide reliable guarantee for the development of modern electrical engineering technology. This can highlight the core competitiveness of technology-oriented enterprises; increase the characteristics of electronic products research and development efforts; improve its service level; enhance the stability of their own development; make sure that electronic engineering modern 
technology development adapted to the enterprise economic growth point construction; enlarge the range of all kinds of electronic engineering technology.

Clear the electronic engineering modernization technology to broaden the key points in various fields. In order to make the field of electronic engineering development of modern technology expanded, we need to make clear these broaden points in different fields. The specific performance in such aspects: (1)Electronic engineering enterprises should improve their capability of independent innovation; rational use of various policies; strengthen cooperation between the education and the cultural departments; broaden the application field of electronic engineering products, and create favorable conditions for the development of electronic engineering technology. These technologies can make a stable development of state in long-term; (2)We should pay attention to the construction of multi-level development model of the modern electronic engineering technology research and development; strengthen technological innovation; broaden the financing channels; achieve a major breakthrough in the key technology in electronic engineering.

\section{Conclusion}

We need to promote the development of modern technology of electronic engineering, so as to accelerate the pace of electronic engineering construction; expand its actual service scope, provide a reliable guarantee for the stable development of China's electronics industry. Therefore, we need to combine with the actual conditions of the modern electronic engineering technology; take the necessary measures for the modernization technology to create favorable conditions. We give the actual effect of various measures for comprehensive evaluation from different aspects; promote the modernization of our country electronic engineering technology development level always staying at a higher level; realize these technology application field expanded. At the same time, countries need to formulate more policies for the research of the electronic engineering and the development of modern technology; increase the training of professional and technical personnel; improve the protection of intellectual property rights. We can lay a solid foundation for the popularization and application of electronic engineering modernization technology.

\section{Reference}

[1] Wang Boyu. Development trend of electronic engineering modernization technology [J]. Information Communication, 2014, (02).

[2] Dong Huan Huan, He Yi. Analysis of modern technology of electronic information engineering [J]. Science and Technology Economic Market, 2016, (02).

[3] Shao Yang. The current situation of the development of modern technology and modern marketing [J]. Modern marketing, 2016, (05).

[4] Li Yibo. Modern technology of electronic engineering [J]. Non-State Running Science \& Technology Enterprises, 2016, (07).

[5] Liu Weixing. Development trend of electronic engineering modernization technology [J]. Computer CD Software and Applications, 2014, (23).

[6] Fang Yan. Analysis of modern application of electronic information engineering [J]. Wireless Internet Technology , 2015, (12).

[7] Zhang Jinju. Analysis of modern technology of electronic information engineering [J]. economic practice, 2015, (09). 